\title{
Dose finding of melatonin for chronic idiopathic childhood sleep onset insomnia: an RCT
}

\author{
Ingeborg M. van Geijlswijk • \\ Kristiaan B. van der Heijden • A. C. G. Egberts • \\ Hubert P. L. M. Korzilius • Marcel G. Smits
}

Received: 24 March 2010 / Accepted: 12 July 2010 /Published online: 29 July 2010

(C) The Author(s) 2010. This article is published with open access at Springerlink.com

\begin{abstract}
Rationale Pharmacokinetics of melatonin in children might differ from that in adults.

Objectives This study aims to establish a dose-response relationship for melatonin in advancing dim light melatonin onset (DLMO), sleep onset (SO), and reducing sleep onset
\end{abstract}

I. M. van Geijlswijk ( $₫)$

Department of Pharmacy, Faculty of Veterinary Medicine,

Utrecht University,

Yalelaan 106,

3584 CM Utrecht, The Netherlands

e-mail: i.m.vangeijlswijk@uu.nl

I. M. van Geijlswijk • A. C. G. Egberts

Department of Pharmacoepidemiology and Pharmacotherapy,

Faculty of Science,

Utrecht Institute for Pharmaceutical Sciences (UIPS),

Utrecht University,

Utrecht, The Netherlands

\section{K. B. van der Heijden}

Department of Clinical Child and Adolescent Studies,

Faculty of Social Sciences, University of Leiden,

Leiden, The Netherlands

\section{A. C. G. Egberts}

Department of Clinical Pharmacy,

Division of Laboratory and Pharmacy,

University Medical Centre Utrecht,

Utrecht, The Netherlands

H. P. L. M. Korzilius

Institute for Management Research,

Radboud University Nijmegen,

Nijmegen, The Netherlands

M. G. Smits

Department of Sleep-Wake Disorders and Chronobiology,

Gelderse Vallei Hospital Ede,

Ede, The Netherlands latency (SOL) in children between 6 and 12 years with chronic sleep onset insomnia (CSOI).

Methods The method used for this study is the randomized, placebo-controlled double-blind trial. Children with CSOI $(n=72)$ received either melatonin $0.05,0.1$, and $0.15 \mathrm{mg} / \mathrm{kg}$ or placebo during 1 week. Sleep was assessed with log and actigraphy during this week and the week before. Outcomes were the shifts in DLMO, SO, and SOL.

Results Treatment with melatonin significantly advanced SO and DLMO by approximately $1 \mathrm{~h}$ and decreased SOL by $35 \mathrm{~min}$. Within the three melatonin groups, effect size was not different, but the circadian time of administration (TOA) correlated significantly with treatment effect on $\operatorname{DLMO}\left(r_{\mathrm{s}}=-0.33, p=0.022\right)$ and SO $\left(r_{\mathrm{s}}=-0.38, p=0.004\right)$, whereas clock TOA was correlated with SO shift $(r=-0.35$, $p=0.006$ ) and not with DLMO shift.

Conclusions No dose-response relationship of melatonin with SO, SOL, and DLMO is found within a dosage range of $0.05-0.15 \mathrm{mg} / \mathrm{kg}$. The effect of exogenous melatonin on $\mathrm{SO}, \mathrm{SOL}$, and DLMO increases with an earlier circadian TOA. The soporific effects of melatonin enhance the SO shift. This study demonstrates that melatonin for treatment of CSOI in children is effective in a dosage of $0.05 \mathrm{mg} / \mathrm{kg}$ given at least 1 to $2 \mathrm{~h}$ before DLMO and before desired bedtime.

Keywords Melatonin treatment · Elementary school-aged children $\cdot$ Chronic sleep onset insomnia $\cdot$ Randomized placebo controlled $\cdot$ Dose finding

\section{Introduction}

Prevalence of chronic sleep onset insomnia in the nondisabled school-aged population is approximately $10 \%$ (Blader et al. 
1997). A chronically reduced sleep due to insomnia may induce various cognitive and behavioral problems in children as well as more widespread difficulties within their families (Dahl 1996; Blader et al. 1997; Ring et al. 1998). It has even been suggested that the current attention-deficit hyperactivity disorder (ADHD) epidemic might partly be attributable to delayed sleep phase disorder, due to a shared underlying pathophysiology or to misinterpretation of daytime consequences of insomnia as ADHD symptoms (Szeinberg et al. 2006).

Chronic sleep onset insomnia in children is often associated with a delayed time at which endogenous melatonin concentration starts to rise in dim light (DLMO) indicating that the biological clock rhythm in these children is set at a later clock time than desired (Van der Heijden et al. 2005). The DLMO is a convenient parameter, as it can usually be obtained before - instead of during — sleep time and is more reliable than many other endocrine or temperature markers of the circadian pacemaker (Klerman et al. 2002). Administration of exogenous melatonin in children with insomnia shifts DLMO as well as sleep onset to an earlier time in the evening, thereby ameliorating the insomnia problems (Smits et al. 2001, 2003; Van der Heijden et al. 2007). The direction, a phase advance or phase delay, and the magnitude of the response of the circadian pacemaker to exogenous melatonin depends on the timing of administration of melatonin relative to the rhythm phase of the pacemaker, the so-called phase response curve. The phase response curve illustrates that the largest phase-advancing therapeutic effects of melatonin can be expected when administration occurs approximately 5 to $6 \mathrm{~h}$ before the individual DLMO. Lewy et al. (2004) were the first to describe this in blind people with a freerunning sleep-wake rhythm. Van der Heijden et al. (2005) demonstrated that the earlier (within a window of 3/4-6 h before DLMO) melatonin is administered in children with sleep onset insomnia and normal vision, the larger the phase advance of sleep onset is.

Since melatonin administration in the afternoon has the potential to cause undesired direct soporific effects, administration in children usually takes place in the early evening, preferably not earlier than $18 \mathrm{~h}$. Most studies apply a melatonin dosage of $5 \mathrm{mg}$, although melatonin plasma concentrations in children are generally higher than in adults due to the fixed size of the pineal gland in humans during development, while the body volume increases (Waldhauser et al. 1988; Schmidt et al. 1995; Griefahn et al. 2003). Children metabolize melatonin, however, more quickly than adults (Cavallo and Dolan 1996; Cavallo and Ritschel 1996). Consequently, the dose-response relationship of melatonin in children may differ from that in adults.

Several small studies and case reports on the efficacy of melatonin for childhood insomnia have been published, with pharmacological doses of $2-12 \mathrm{mg}$. These studies showed that melatonin treatment is effective and safe in children with sleep onset disorders with or without comorbidity (Jan et al. 1994, 2000; McArthur and Budden 1998; Jan 2000; Smits et al. 2001, 2003; Coppola et al. 2004; Weiss et al. 2006; Van der Heijden et al. 2007; Wasdell et al. 2008). The applied dosage of melatonin in these studies is very diverse, and - except in one study (Van der Heijden et al. 2007) — not adjusted to age or bodyweight. This is at least exceptional, in comparison to other drug regimens in children. Most drugs are dosed in children in relation to their bodyweight.

Recently, several reviews concluded that melatonin is effective and safe in children irrespective of the dosage (Pandi-Perumal et al. 2007; Owens and Moturi 2009; Bendz and Scates 2010). So, a knowledge gap remains as to the dosage of melatonin in children. The aim of the present trial was to assess the dose-effect relationship of melatonin in advancing the sleep-wake rhythm in elementary school children aged 6-12 years suffering from chronic sleep onset insomnia and to find the most appropriate dosage with the largest effect and least adverse events.

With the results of a trial of short length and noninvasive measurements, we intend to contribute to evidence-based medicine and, therefore, to rational drug prescription in children (Sutcliffe and Wong 2006; Vitiello 2007) suffering from insomnia, finding the appropriate dosage of melatonin.

\section{Methods and materials}

\section{Study design}

The trial consisted of two consecutive periods: a 1-week qualification period and 1 week of treatment, in which participants were randomly and evenly allocated to one of the doses of melatonin or to placebo.

The trial was performed according to the 1997 European Guidelines for Good Clinical Research Practice in children and followed the 1983 revised provisions of the 1975 Declaration of Helsinki.

The protocol was approved by the institutional review board as a mono-center trial by the Central Committee on Research Involving Human Subjects and registered in the International Standard Randomized Controlled Trial Number Register (ISRCTN20033346).

\section{Participants}

Children who suffered from chronic sleep onset insomnia were referred by their general practitioner, pediatrician, or child psychiatrist to the Centre for Sleep-Wake Disorders and Chronobiology of the Hospital Gelderse Vallei Ede. 
Children were eligible if they were 6-12 years old, suffering from sleep onset insomnia more than four nights a week for more than 1 year, and insufficiently responded to sleep hygiene improving measures based on parental reports. Sleep onset insomnia was defined as sleep onset later than 8:30 p.m. in children aged 6 years and for older children 15 min later per year until age 12 (10:00 p.m.). Furthermore, the latency between lights-off time and sleep onset (sleep onset latency) had to be more than $30 \mathrm{~min}$ on average. Their sleep onset had not been advanced sufficiently with the usual sleep hygiene improving measures (Lam and Mason 2007). Further inclusion criteria were normal sleep architecture as indicated by a normal hypnogram, performed within 2 months prior to participation, and written informed consent obtained from parents. Exclusion criteria were chronic sleep onset insomnia due to psychiatric or pedagogic problems, known intellectual disability, pervasive developmental disorder, chronic pain, known disturbed hepatic or renal function, epilepsy, prior use of melatonin, and use of stimulants, neuroleptics, benzodiazepines, clonidine, antidepressants, hypnotics, or beta-blockers within 4 weeks before enrollment.

Finally, DLMO was determined by saliva measurements before inclusion as described elsewhere (Nagtegaal et al. 1998) to validate the diagnosis of DSPD.

\section{Interventions}

During the treatment week, all participants took medication on nights 1-6 between 17:30 and 19:30, placebo or melatonin 0.05 or 0.1 or $0.15 \mathrm{mg} / \mathrm{kg}$ (constituting four treatment groups). The children and their parents were instructed to administer the trial medication every day at the same time, depending on age and designated bedtime. For practical reasons, we aimed at $1.5-2 \mathrm{~h}$ before bedtime. This way, we ensured to be in the previously mentioned timeframe of preferred time of administration (TOA). The time of administration was recorded in the sleep diary every evening.

Participants were not allowed to have their comedication changed. Both weeks had to be regular school weeks, at least 2 weeks after time-shift weeks (summertime/ wintertime), and preferably without parties, school camps, holidays, etc.

Compliance of the medication was assessed by counting the number of capsules returned.

\section{Outcomes}

Sleep: sleep onset, sleep onset latency, wake-up time, and total sleep time

During the baseline and treatment periods, the parents recorded lights-off time, sleep onset, and wake up time daily in a sleep $\log$ (on paper or online in a specialized internet software application (Medsys/De Nieuwe Coster/ 2004)); additional information on mood and adverse events were also recorded.

During all 14 days of the trial, participants were instructed to wear an actigraph (Cambridge Neurotechnology) from the moment they went to bed until the moment they got up in the morning (get-up time). This motion-sensing device - the size of a normal wristwatch - was attached to the non-dominant wrist. Actigraphic monitoring measured movements in 30-s periods. It is a validated method to assess sleep patterns in children (Morgenthaler et al. 2007; Werner et al. 2008). Actigraphic data were converted into sleep parameters by the validated automatic Actiwatch scoring algorithm, combined with subsequent manual verification based on sleep logderived bedtime and get-up time (Kushida et al. 2001). Sleep onset ( $\mathrm{SO}$ ) and wake-up time, as derived from the wrist activity records, averaged over three to seven nights of each week and were estimated as described elsewhere (Littner et al. 2003). Sleep onset latency (SOL) and total sleep time (TST) were calculated $(\mathrm{SOL}=\mathrm{SO}-$ bed time and $\mathrm{TST}=$ wake up time-SO). Sleep $\log$ data were used to validate the actigraphy data; in case of discrepancy, the actigraphy data prevailed.

\section{Dim light melatonin onset}

On the last nights of the baseline and the treatment week, five saliva samples were collected by chewing on a cotton plug during 1 min (Salivetten, Sarstedt Nümbrecht, Germany) at 19:00, 20:00, 21:00, 22:00, and 23:00 h. In the treatment week, at this night, no trial medication was used. Salivary melatonin concentrations were measured as described elsewhere (Nagtegaal et al. 1998). To prevent suppression of melatonin secretion by bright light (Bojkowski et al. 1987) during the collection period, the children were instructed to stay in bed or in the living room, with closed curtains and only dim light allowed, $40 \mathrm{~lx}$ (Brainard et al. 2000). DLMO was defined as the time at which salivary melatonin concentration reaches $4 \mathrm{pg} / \mathrm{ml}$ and was calculated by linear interpolation between the two samples just below and just above $4 \mathrm{pg} / \mathrm{ml}$.

\section{Sample size}

Based on results of a previous study of melatonin in a similar population (Smits et al. 2001), sample size calculation with the SPSS Sample Power 2.0 program showed that 26 subjects in the melatonin-treatment group and 26 subjects in the placebo-treatment group are needed to find a significant $(p<0.05$; power 0.90 ; one tailed) advance (SD) sleep onset of 67 (85) min compared to an advance (SD) of 10 (46) $\mathrm{min}$ in the placebo group. When 
four subjects have to be excluded in each treatment group, 30 subjects can be considered to be enough to find a significant advance of sleep onset time. For four treatment groups, the planned sample size was 120 participants to be recruited within 3 years.

\section{Randomization}

For this trial, a specialized internet software application (Medsys/De Nieuwe Coster/2004) was developed for randomization of participants, for calculation of the assigned dose (based on body weight), and for collection of sleep log data.

Patients were randomized in blocks of eight to keep possible seasonal time effects to a minimum.

During a visit with the neurologist, eligible patients were invited to participate in Meldos and, if willing, added to the database Medsys. Afterwards, the hospital pharmacist made a telephone call to check willingness, to make an appointment, and to randomize participants in Medsys. For this appointment, the hospital pharmacy prepared the appropriate trial medication and programmed the actigraph. During the visit, the hospital pharmacist handed over all materials (actigraph, salivettes, medication, and sleep log) and gave instructions.

\section{Blinding}

The assigned dose of melatonin was ad hoc prepared by one of the hospital pharmacy technicians in capsules, containing only microcrystalline cellulose (Bufa, Haarlem, The Netherlands) as placebo or containing melatonin (melatonin supplied by Pharma Nord, Denmark) in the appropriate calculated dosage and microcrystalline cellulose. The capsules were packed in unit dose strips, labeled with "Melatonine $\times$ mg" masked with an X to keep participants blind to the treatment allocation and subject number.

All participants, care providers, and investigators involved in the study were unaware of the treatment allocation.

Data analysis

The time measurements bed-, sleep onset, wake-up, and get-up time was expressed in $24 \mathrm{~h} / \mathrm{min}$.

The difference (shift) between baseline and treatment week for DLMO and mean sleep measures (SO, SOL, and TST) was calculated for each participant individually.

This way, we assessed individual responses to one of the treatments. These shifts were expressed in hours minute or minutes alone and the means per treatment group (mean $( \pm \mathrm{SD}))$ were compared.

Comparisons of demographic and clinical characteristics between treatment groups were conducted using independent samples Student's $t$ test for continuous variables with a normal distribution and Mann-Whitney $U$ test when distribution was not normal, using SPSS 15.0 for Windows (SPSS Inc. 2006).

We wanted to differentiate between dosing effects and timing effect in the observed baseline-treatment week shifts of DLMO, SO, and SOL. Second-degree polynomial trend line estimation in Microsoft Office Excel 2003 (Microsoft Inc 1985-2003) and quadratic curve fit and two-tailed correlation analysis (Pearson and Spearman's $r_{\mathrm{s}}$; SPSS 15.0) were used to assess timing effect. We studied all shifts as function of clock TOA and as function of circadian TOA. The circadian TOA is determined by defining DLMO as CT14 (Lewy et al. 1999); a clock TOA $2 \mathrm{~h}$ before DLMO means a circadian TOA of CT12.

Additionally, shifts of DLMO, SO, and SOL were studied in relation to the baseline individual circadian alignment, characterized by the phase angle difference (PAD). PAD reflects the time distance between baseline DLMO and baseline mid-time of sleep measured by actigraphy (Lewy et al. 2006).

We first analyzed the effect of melatonin treatment (different dosages) compared to placebo. Then, we analyzed the differences between the different melatonin dosages. The latter analyses required exclusion of the placebo group as a considerable part of the correlation between dosage and outcome parameters is due to the difference between placebo and melatonin and not to differences between the different dosages of melatonin.

Wake-up time and total sleep time data are not analyzed since those data were found to be strongly influenced by fixed wake-up time.

\section{Results}

Baseline demographic and clinical characteristics

Initially, 88 children were found eligible to participate in this study. Due to several reasons (logistic problems due to shortage of actigraphs, holidays, social activities, attending high school, winter/summertime shift, unexpected family circumstances, and not allowed-co medication), 16 children were excluded before randomization (Fig. 1).

Based on the results of interim analyses of data of the 72 included children during a period of almost 3 years, the decision was made to finish recruitment instead of extending the trial over a longer period of time. The trial was conducted between May 2004 and February 2007.

Table 1 shows demographic characteristics of participants per treatment group, including bed and medication times; the participants were encouraged not to change bedtime and getup time during the 2 weeks. 
The mean $( \pm \mathrm{SD})$ bedtime, measured by actigraphy, averaged over the four treatment groups was 20:41 $( \pm 0: 41) \mathrm{h}$ in the baseline week and 20:33 $( \pm 0: 33) \mathrm{h}$ in the treatment week. Mean get-up time was 07:40 $( \pm 0: 23) \mathrm{h}$ at baseline and 07:39 $( \pm 0: 25) \mathrm{h}$ in the treatment week. Both weeks are comparable in events (ordinary [school] weeks, no special days or activities); observed effects on sleep parameters can, therefore, be attributed to the melatonin administration. Get-up time was for most days, and most children clearly restricted due to school times and, therefore, excluded from evaluation as a treatment result. At baseline, there were no significant between-group differences in demographic variables.

Seventy-two children were randomized to one of the four treatment arms. Actigraphic data were collected from 67 participants, and DLMO was determined in 62 participants. Two children ended participation after randomization but before the start with the trial medication: one boy because his mother was concerned that he would see the actigraph as a challenge to stay awake as long as possible, the second child because of diagnosis of mononucleosis infectiosa, just prior to starting.

Three children forgot to wear the actigraph the second week and were, for that reason, excluded from actigraphic data analysis.

The analysis was based on $5.3( \pm 0.87)$ nights (mean $( \pm \mathrm{SD}))$.

Two children forgot to collect saliva samples and were, for that reason, excluded from DLMO analysis. Additionally, in six children, the DLMO could not be calculated because the first salivary level at 19:00 $\mathrm{h}$ was already higher than $4 \mathrm{pg} / \mathrm{ml}$ (DLMO reached), resulting in blank values. The five collected saliva samples were not suitable for determination of individual thresholds like Voultsios and Burgess did (Voultsios et al. 1997; Burgess et al. 2008) as the timing was aimed at

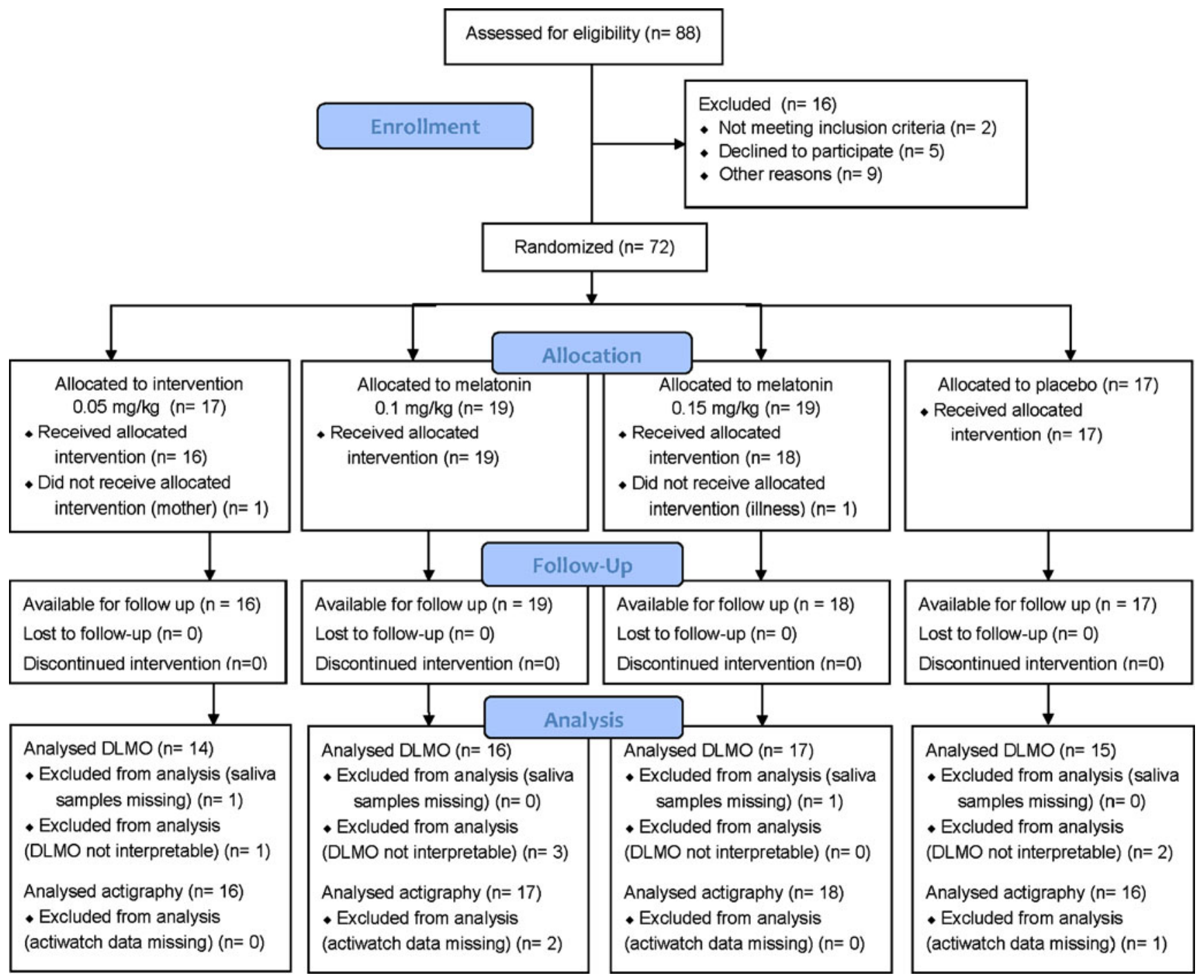

Fig. 1 Randomization scheme and justification of obtained outcome data (per group actigraphy and DLMO data obtained within the same group of included participants) 
Table 1 Demographic characteristics of participants

TOA time of administration

\begin{tabular}{|c|c|c|c|c|c|c|}
\hline & \\
\hline & \multicolumn{2}{|l|}{ Dose (mg/kg) } & \multirow{2}{*}{$\frac{0.05}{16}$} & \multirow{2}{*}{$\begin{array}{c}0.1 \\
19\end{array}$} & \multirow{2}{*}{$\begin{array}{c}0.15 \\
18\end{array}$} & \multirow{2}{*}{$\frac{0}{17}$} \\
\hline & $n$ & & & & & \\
\hline & Bodyweight & Mean & 32 & 31 & 29 & 27 \\
\hline & & Min & 18 & 16 & 16 & 20 \\
\hline & & Max & 45 & 49 & 42 & 35 \\
\hline & & SD & 8 & 8 & 7 & 4 \\
\hline & Dose & Mean & 1.60 & 2.91 & 4.39 & 0 \\
\hline & & Min & 0.9 & 1.4 & 2.4 & 0 \\
\hline & & Max & 2.2 & 4.9 & 6.3 & 0 \\
\hline & & SD & 0.39 & 0.91 & 0.98 & 0 \\
\hline & Age & Mean & 9.5 & 8.9 & 8.7 & 8.7 \\
\hline & & Min & 6.9 & 6.5 & 6.0 & 6.2 \\
\hline & & Max & 11.7 & 11.6 & 11.3 & 11.8 \\
\hline & & $\mathrm{SD}$ & 1.8 & 1.4 & 1.4 & 2.8 \\
\hline & Boys (\%) & & $9(56 \%)$ & $5(26 \%)$ & $10(56 \%)$ & $6(35 \%)$ \\
\hline & Bedtime week 1 & Mean & $20: 52$ & $20: 48$ & $20: 38$ & $20: 27$ \\
\hline & & Min & 19:03 & $19: 49$ & $19: 56$ & $19: 25$ \\
\hline & & Max & $22: 40$ & $22: 06$ & $21: 26$ & $21: 40$ \\
\hline & & SD & $0: 59$ & $0: 34$ & $0: 28$ & $0: 34$ \\
\hline & Bedtime week 2 & Mean & $20: 44$ & $20: 35$ & $20: 26$ & $20: 25$ \\
\hline & & Min & $19: 13$ & $19: 58$ & $19: 25$ & $19: 35$ \\
\hline & & Max & $21: 34$ & $21: 21$ & $21: 14$ & $21: 02$ \\
\hline & & $\mathrm{SD}$ & $0: 50$ & $0: 26$ & $0: 26$ & $0: 24$ \\
\hline & Clock TOA & Mean & $19: 15$ & 19:08 & 19:11 & $18: 59$ \\
\hline & & Min & $17: 58$ & $18: 15$ & $18: 30$ & 18:08 \\
\hline & & Max & $20: 17$ & $20: 42$ & $20: 20$ & 20:00 \\
\hline & & SD & $0: 41$ & $0: 36$ & $0: 32$ & $0: 25$ \\
\hline & Get-up time week 1 & Mean & $7: 41$ & $7: 41$ & $7: 41$ & $7: 38$ \\
\hline & & Min & $7: 14$ & $7: 11$ & $7: 14$ & $7: 17$ \\
\hline & & Max & $9: 18$ & $8: 55$ & $8: 24$ & 8:09 \\
\hline & & SD & $0: 32$ & $0: 25$ & $0: 18$ & $0: 16$ \\
\hline & Get-up time week 2 & Mean & $7: 39$ & $7: 41$ & $7: 32$ & $7: 48$ \\
\hline & & Min & 7:01 & $7: 11$ & $6: 53$ & $7: 05$ \\
\hline & & Max & $8: 36$ & $8: 47$ & $8: 31$ & $8: 33$ \\
\hline & & $\mathrm{SD}$ & $0: 25$ & $0: 26$ & $0: 26$ & $0: 24$ \\
\hline
\end{tabular}

determination of DLMO. For this reason, we adhered to the traditional definition of DLMO (saliva $4 \mathrm{pg} / \mathrm{ml}$ ).

The parents of $25(35 \%)$ children did report most results online; the other parents filled in the print out. These data were added to the database afterwards.

Seventy-two children received seven capsules each. Two children returned the medication unused. One child returned two capsules because his mother decided to advance the second DLMO test due to bedwetting (three nights in a row). Eight children returned zero capsules: five because of postponing the final DLMO test for social reasons, three because the remaining capsule was used afterwards because its effect was much appreciated.
TOA, as daily recorded in the sleep diary, was related to age and varied between 17:58 and 20:42 h (mean 19:08 0:34 (SD); Table 1).

\section{Co-medication}

Ten participants reported use of co-medication during the trial, two in groups 1 and 4 and three in groups 2 and 3 . Four participants used anti-histaminics: desloratadine, ketotifen, levocetirizine, hydroxyzine; five participants used methylphenidate. One participant used fluticason and salbutamol by inhalation, and one participant used valproic acid, trimethoprim, and lactitol. 
Table 2 Comparison of DLMO and sleep measures sleep onset and sleep onset latency between the three melatonin dosage groups and placebo

\begin{tabular}{|c|c|c|c|c|c|c|}
\hline \multirow{2}{*}{$\begin{array}{l}\text { Dose } \\
\mathrm{mg} / \mathrm{kg}\end{array}$} & \multirow{2}{*}{$\begin{array}{l}\text { Mean difference in comparison to placebo group } \\
\text { a } \\
\text { h:m }\end{array}$} & \multirow{2}{*}{$\begin{array}{l}\text { Standard error of the difference } \\
\text { h:m }\end{array}$} & \multicolumn{2}{|c|}{$\begin{array}{l}95 \% \text { Confidence } \\
\text { interval of the } \\
\text { difference }\end{array}$} & \multirow[t]{2}{*}{$d f$} & \multirow[t]{2}{*}{$p$ Value } \\
\hline & & & Lower & Upper & & \\
\hline \multicolumn{7}{|l|}{0.05} \\
\hline DLMO shift & $1: 05$ & $0: 32$ & $-0: 01$ & $2: 12$ & 22.6 & 0.053 \\
\hline SO shift & $0: 42$ & $0: 10$ & $0: 20$ & $1: 03$ & 29.6 & $<0.001$ \\
\hline $\begin{array}{l}\text { SOL shift } \\
0.1\end{array}$ & $0: 31$ & $0: 10$ & 0:09 & $0: 54$ & 29.6 & 0.007 \\
\hline DLMO shift & $1: 45$ & $0: 26$ & $0: 53$ & $2: 38$ & 29.0 & $<0.001$ \\
\hline SO shift & $0: 50$ & $0: 11$ & $0: 27$ & $1: 13$ & 29.6 & $<0.001$ \\
\hline $\begin{array}{l}\text { SOL shift } \\
0.15\end{array}$ & $0: 36$ & $0: 10$ & $0: 15$ & $0: 57$ & 30.7 & 0.001 \\
\hline DLMO shift & $1: 31$ & $0: 24$ & $0: 41$ & $2: 21$ & 30.7 & $<0.001$ \\
\hline SO shift & $0: 56$ & $0: 10$ & $0: 34$ & $1: 18$ & 29.7 & $<0.001$ \\
\hline SOL shift & $0: 42$ & 0:09 & $0: 22$ & $1: 02$ & 31.5 & $<0.001$ \\
\hline
\end{tabular}

Equal variances not assumed

$D L M O$ dim light melatonin onset, $S O$ sleep onset, $S O L$ sleep onset latency

${ }^{\text {a }}$ Positive value $=$ phase advance, negative value $=$ phase delay

\section{$D M L O, S O$, and $S O L$ results}

DLMO was delayed by 16 min in the placebo group and was advanced by $50-90 \mathrm{~min}$ in the melatonin treatment groups. SO was advanced by $9 \mathrm{~min}$ in the placebo group and 51$66 \mathrm{~min}$ in the melatonin treatment groups. SOL was reduced by $12 \mathrm{~min}$ in the placebo group and by $43-54 \mathrm{~min}$ in the melatonin treatment groups.
Table 2 shows the comparison of three melatonin treatments $(0.05,0.1$, and $0.15 \mathrm{mg} / \mathrm{kg})$ with placebo.

The DLMO advance in the 0.1 and $0.15 \mathrm{mg} / \mathrm{kg}$ treatment group was significantly $(p<0.001)$ different from placebo; the $0.05 \mathrm{mg} / \mathrm{kg}$ group did not reach significance $(p=0.053)$.

$\mathrm{SO}$ advanced in all three melatonin groups compared to placebo; the SO shift difference between melatonin treat-
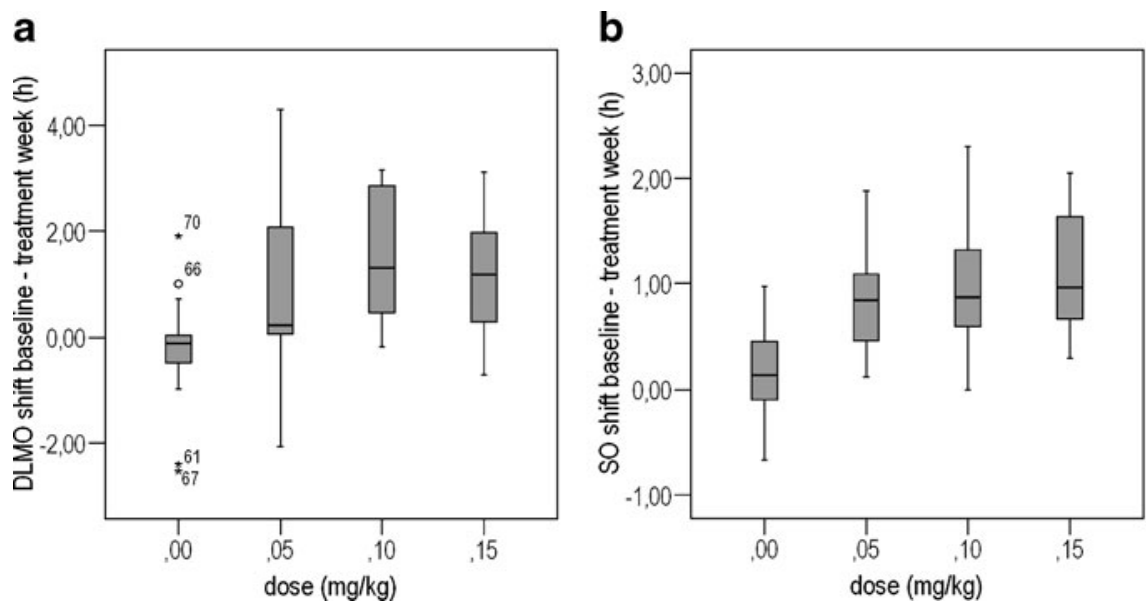

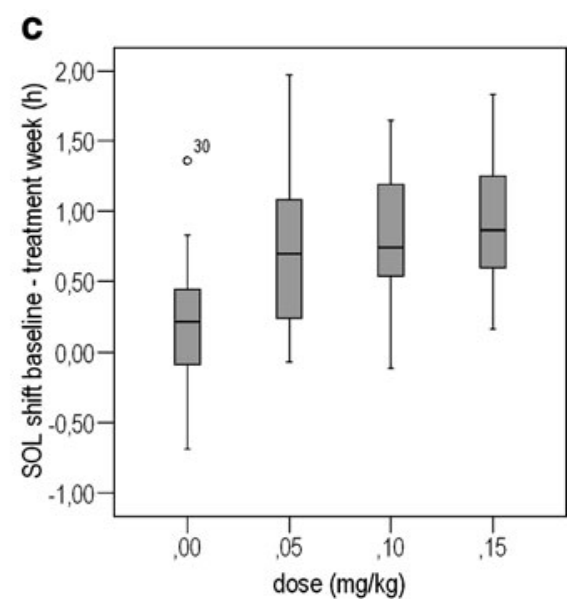

Fig. 2 a DLMO (threshold $=4 \mathrm{pg} / \mathrm{ml}$ ) advance (individual differences between baseline and treatment week) in the four treatment groups. b SO shift (individual differences between baseline and treatment week) in the four treatment groups. c SOL reduction (individual differences baseline and treatment week) in the four treatment groups. Solid box upper and lower quartiles, box length contains the middle $50 \%$ of the data (IQR); line median, lines extending from box (whiskers) the distance to the largest and smallest observations that are less than one quartile range from the box, dots $O$ outliers $(>1.5 \times \mathrm{IQR}) \times=$ extremes $(>3 \times \mathrm{IQR}) . D L M O$ dim light melatonin onset, $S O$ sleep onset, $S O L$ sleep onset latency 
Fig. 3 a DLMO, SO, and SOL shifts with clock TOA in the three melatonin-treatment groups. b DLMO, SO, and SOL shifts with circadian TOA in the three melatonin-treatment groups
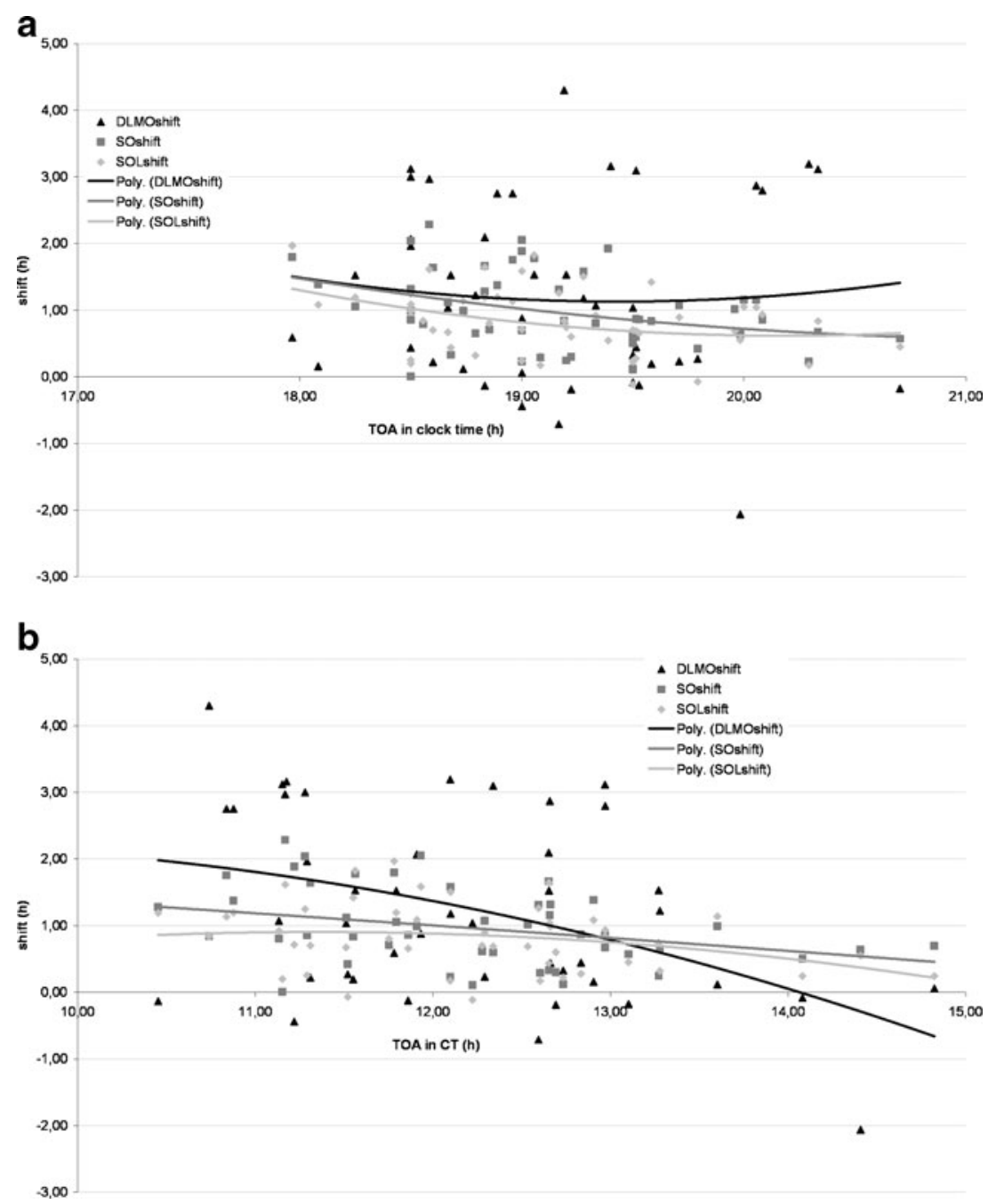

ment and placebo treatment is $42-56 \mathrm{~min}$, which is significant $(p<0.001)$ for all melatonin groups.

SOL was reduced in all three melatonin groups compared to placebo. The difference between placebo treatment and melatonin treatment for SOL shift was 31$42 \mathrm{~min}$, and the reduction of SOL differed significantly in all three treatment groups from placebo $(p=0.007$, $p=0.001$, and $p<0.001)$.

\section{Dose-response relationship versus time-response} relationship

The shifts of DLMO, SO, and SOL are visualized in Fig. $2 \mathrm{a}-\mathrm{c}$.

Because no clear dose-response relationship was detected in all groups, the individual time of administration of melatonin relative to baseline DLMO were calculated (circadian TOA). Shifts of DLMO, SO, and SOL in the three groups with melatonin were plotted as function of clock TOA (Fig. 3a) and as function of circadian TOA
(Fig. 3b). These figures demonstrate the relationship of the DLMO shift with circadian TOA and not with clock TOA. On the contrary, for SO and SOL shifts, the TOA relationship does not show distinct differences between clock TOA and circadian TOA.

PAD was significantly correlated to the DLMO shift, but not to the SO and SOL shift (Fig. 4).

Curve fitting of DLMO shift (of the three melatonin groups) with TOA expressed in relative Circadian Time, with DLMO (CT14) as reference point $=0$ according to Burgess et al. (2008) resulted in the small part of the expected PRC of melatonin $\left(R^{2}=0.175, p=0.015\right.$; Fig. 5a). Dosage differentiation did not result in distinct curves due to the small number of subjects per dose $(n=16-19)$.

Curve fitting of SO shift versus TOA in relation to baseline DLMO resulted in distinct curves for all groups (Fig. 5b). For the higher doses, a bigger shift was noted with an early TOA; for the TOA closer to the DLMO, this dose relationship disappeared. 
Fig. 4 DLMO, SO, and SOL shifts with PAD in the three melatonin-treatment groups

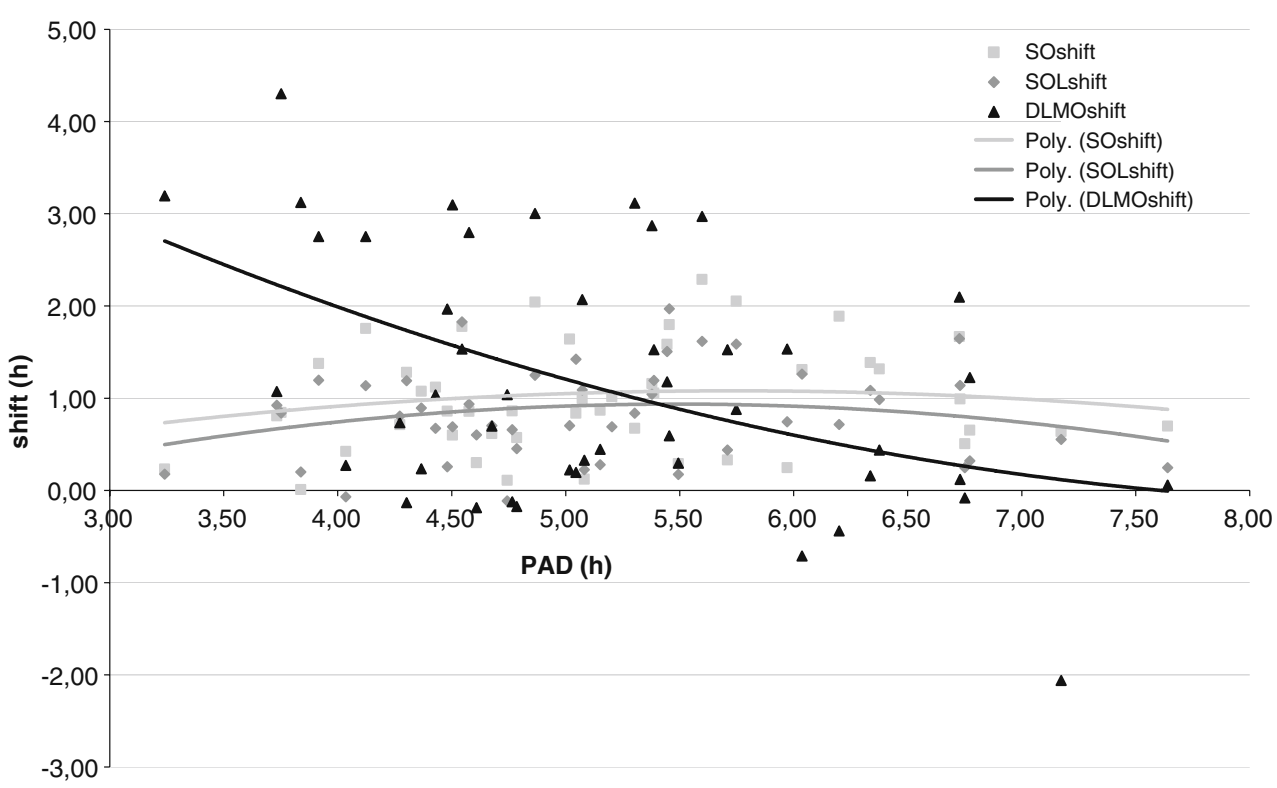

In the bivariate correlation analysis, the dose was significantly correlated with all outcome parameters (DLMO, SO, and SOL shift), as was the circadian TOA, when tested in all treatment groups.

DLMO shift was correlated with SO shift and SOL shift as well (Spearman correlation $r_{\mathrm{s}}=0.38, p=0.003$ and $r_{\mathrm{s}}=$ $0.36, p=0.05)$. None of the sleep outcome parameters appeared to be significantly related to clock TOA, in contrast to the circadian TOA.

After exclusion of the placebo group from analysis, correlation of all sleep parameters with dosage disappeared, as did the previous association of the DLMO shift with SO shift and SOL shift (Table 3). After exclusion of placebo, correlation between SO shift and clock TOA became significant, in addition to the relation with circadian TOA. For SOL shift, exclusion of the placebo group resulted in an additional correlation with clock TOA and in disappearance of the correlation with the circadian TOA. All correlations with TOA are negative, indicating a larger shift when medication is taken earlier.

DLMO shift was significantly correlated to PAD and circadian TOA, and not to clock TOA (Table 3).

\section{Adverse effects}

The most common adverse events were red cheeks, red earlobes, and red eyes and yawning within an hour after administration $(n=15)$; pale looks, dizziness, and cold feelings (eight); headache (two); nausea and stomachache (one); and dizziness and nausea (one). Most of the adverse events wore off during the treatment week. Headache and stomachache were reported in the placebo group, not in the melatonin-treatment groups. The sleep-related adverse events (red cheeks or rather pale looks, cold feelings) and dizziness were reported in the three melatonin groups; the frequency was related to dosage $(0.15: 0.1: 0.05=5: 4: 3)$. One participant ended the treatment period early due to bedwetting, attributed to the medication by his mother $(0.05 \mathrm{mg} / \mathrm{kg})$. Two other participants reported enhanced urination during the evening and night $(0.1$ and $0.15 \mathrm{mg} / \mathrm{kg})$.

\section{Discussion}

In children with chronic sleep onset insomnia, 1-week treatment with melatonin significantly advanced sleep onset and dim light melatonin onset by approximately $1 \mathrm{~h}$ and reduced sleep onset latency by approximately $35 \mathrm{~min}$, compared to placebo. Surprisingly, there was, within the dosage range of $0.05-0.15 \mathrm{mg} / \mathrm{kg}$, no dose-response relationship of melatonin and shifting of the sleep parameters or DLMO.

It is unlikely that the treatment duration of 1 week was too short to show differences in the efficacy between dosages. Data from earlier studies of melatonin effects on sleep parameters with duration of 5 weeks showed that as early as after the first treatment night, robust treatment effects emerged and that the effects remained stable during the following weeks (Van Geijlswijk et al. 2010).

There may be a point of diminishing returns at a dosage lower than the tested lowest dosage of $0.05 \mathrm{mg} / \mathrm{kg}$. Hence, each additional increase in dosage beyond this dosage yields less and less additional response, until reaching a "ceiling effect," like the upper right part of a traditional dose-response curve. Another possibility is that the dose- 
Fig. 5 a DLMO shift (individual differences between baseline and treatment week) with TOA related to baseline DLMO, for all groups, plotted on top of a 24-h phase response curve adapted from Burgess et al. (2008). b SO shift (individual differences between baseline and treatment week) with TOA related to baseline DLMO in all treatment groups

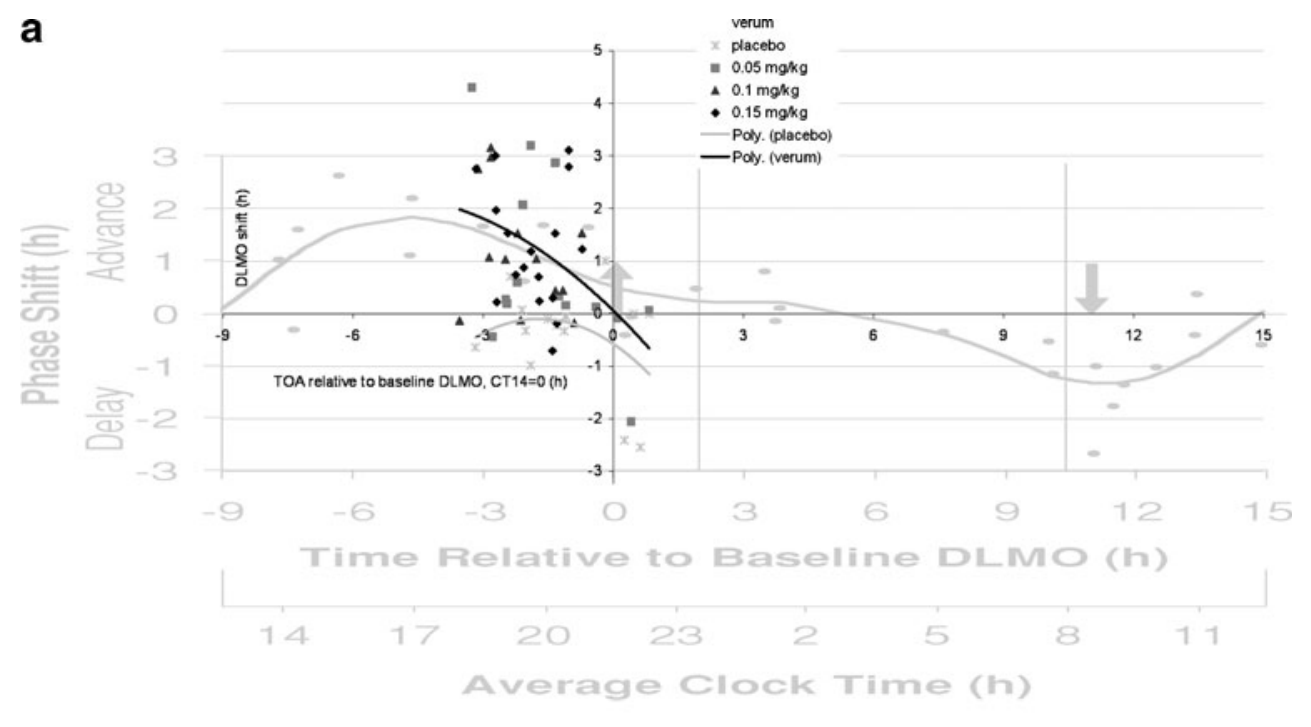

b

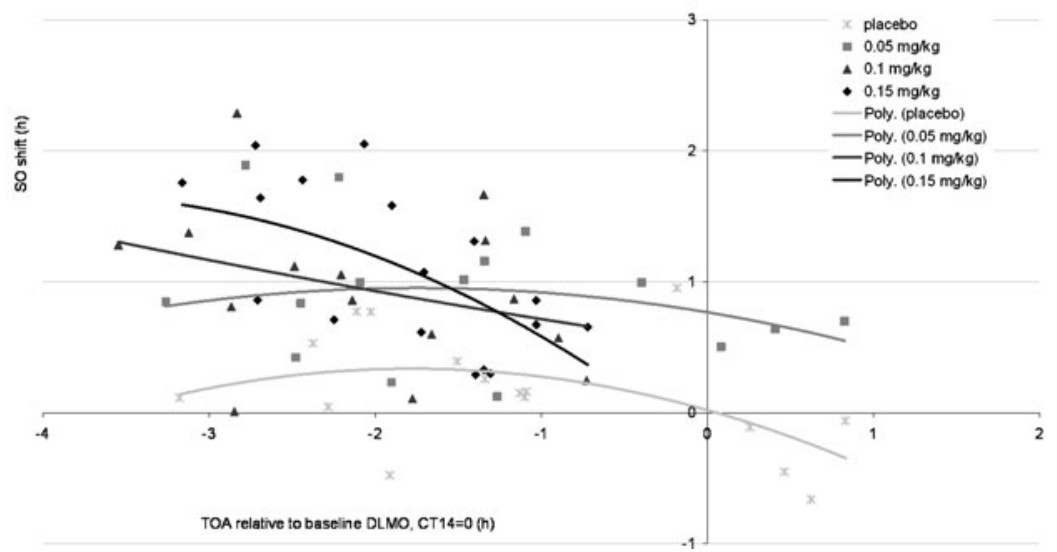

response relationship reflects an "all-or-nothing" principle. That is, all dosages above a certain threshold dose induce similar magnitudes of responses, like the acetylcholine receptor-mediated innervations of motor cells (Ruff 1998). The absence of a dose-response relationship in this study is in line with findings in a sleep-EEG study where melatonin was administrated at 18:00 $\mathrm{h}$ in the dose range of $0.5-10 \mathrm{mg}$ in six healthy adults (Stone et al. 2000).

In contrast, the timing of drug administration seems to have substantial influence on the treatment effect. TOA was recorded daily; the naturalistic design of this study allowed for some flexibility on this aspect. As a result of this, the average TOA on Friday and Saturday was later than the TOA on weekdays. When correcting for circadian TOA, the differences between the $0.05 \mathrm{mg} / \mathrm{kg}$ group and the other two dosing groups for mean DLMO shift disappear. This is at least partly due to the considerably wider range of DLMO-TOA interval values in the $0.05 \mathrm{mg} / \mathrm{kg}$ group that can be attributed to the extreme minimum and maximum results of the DLMO shift ([-2.04]-4.18) within this group.
From a pharmacokinetic point of view, one could argue that the lower the dosage, the shorter the interval between TOA and DLMO should be since melatonin has a very short elimination half-life in most individuals (between 35 and $45 \mathrm{~min}$ ). Recently, the association between time of administration and dosage in relation to endogenous melatonin onset is made (Burgess et al. 2008). It is plausible that very low dosages $(0.5 \mathrm{mg}$ or less $)$ given early ( $5 \mathrm{~h}$ before DLMO) are already cleared to below physiological levels before endogenous melatonin onset occurs, and we expect that no shift of DLMO will be observed (Burgess et al. 2008). This phenomenon might also have contributed to the nonsignificant DLMO shift observed in the $0.05 \mathrm{mg} / \mathrm{kg}$ group, since the maximum of DLMO-TOA interval was similar (low dosage to high dosage $3.27,3.55$, and $3.17 \mathrm{~h}$ ) in all melatonin groups.

SO was significantly advanced by administration of exogenous melatonin. The magnitude of effect was not predicted by dosage but was significantly related to clock TOA and to circadian TOA. Especially, the correlation with clock TOA could imply that the effects on SO and SOL that 
Table 3 Results of bivariate correlation analysis for dosage, PAD, TOA in clock time and in circadian time, and shifts of DLMO, SO, and SOL, tested for melatonin treatment groups $1-3$ $(n=46-53)$

Correlations with DLMO measures (DLMO shift and Circadian TOA) are Spearman correlations; the others are Pearson correlations

$P A D$ phase alignment difference, $D L M O$ dim light melatonin onset, TOA stime of

administration, $S O$ sleep onset, $S O L$ sleep onset latency

\begin{tabular}{lllllll}
\hline & Dosage & PAD & Clock TOA & Circadian TOA & DLMO shift & SO shift \\
\hline PAD & 0.16 & & & & \\
& $p=0.13$ & & & & \\
Clock TOA & -0.05 & -0.18 & & & \\
& $p=0.37$ & $p=0.11$ & & & \\
Circadian TOA & -0.10 & -0.65 & -0.32 & & \\
& $p=0.26$ & $p<0.001$ & $p=0.012$ & & \\
DLMO shift & 0.15 & 0.37 & -0.09 & -0.33 & \\
& $p=0.16$ & $p=0.005$ & $p=0.28$ & $p=0.022$ & \\
SO shift & 0.17 & 0.17 & -0.35 & -0.38 & 0.03 & \\
& $p=0.12$ & $p=0.13$ & $p=0.006$ & $p=0.004$ & $p=0.42$ & 0.75 \\
SOL shift & 0.15 & 0.12 & -0.32 & -0.29 & 0.15 & \\
& $p=0.15$ & $p=0.21$ & $p=0.011$ & $p=0.024$ & $p=0.17$ & $p<0.001$ \\
& & & & &
\end{tabular}

we measured were induced by the direct soporific effects of melatonin rather than by a chronobiotic effect, comparable to the way traditional sedatives act.

There is a methodological difference between measuring the DLMO shift and measuring SO and SOL shifts. Post-treatment DLMOs are determined after a period of melatonin administration; but on the night of melatonin measurements, no exogenous melatonin is administrated. The DLMO shift is, therefore, not influenced by direct effects of administrated melatonin. This is in contrast to the effects on SO shift and SOL shift, which are influenced by melatonin administration on the measurement nights. This might explain the relationship of PAD with DLMO shift, and not with SO and SOL shift, the DLMO shift reflecting exclusively chronobiotic effects. The soporific effect of melatonin improves SO and reduces SOL, which is why individuals with a PAD $\geq 6$ still experience a SO and SOL shift, without a DLMO shift.

The children included all had late DLMOs. A long TOA-DLMO interval in this population will result in a large response to melatonin therapy, in DLMO shift, which is a demonstration of the chronobiotic mechanism, and in SO and SOL shift. In addition to the chronobiotic effect, soporific effects of melatonin will add to the size effect on $\mathrm{SO}$ and SOL. The effect of the same dosage of exogenous melatonin on SO in a normal population can be completely different since this DLMO-TOA interval will be shorter when taken at the same clock TOA. Melatonin administration at the TOA of traditional hypnotics confers risk for the TOA being later than DLMO, thus minimizing the potential for phase advancing the rhythm (Fig. 5a). This may be the mechanism behind the inefficacy of melatonin as an ordinary hypnotic. When timing is correct, the magnitude of effect on SO, SOL, and DLMO is not related to the dose in the threefold dose range we have studied. This supports earlier findings stressing the importance of measuring DLMO before starting melatonin treatment (Hoebert et al. 2009).
A number of potential limitations need to be noted. First, this trial assessed the effects of only 1-week treatment with melatonin. In children with sleep onset insomnia using melatonin, drug-holiday breaks during 1 week result in return of the former sleep pattern in more than $90 \%$ of the users (Hoebert et al. 2009). This implies that the chronobiotic effect can only be sustained with chronic treatment, although in children, the need for advancing sleep onset disappeared in $8 \%$ of the children after 4 years of treatment (Hoebert et al. 2009). For the report of adverse events, long-term studies need to be done. In fact, we did readdress the participants of this trial 1.5-4.6 years after inclusion and evaluated their experiences with prolonged therapy. We will report on this soon.

Second, the groups are small, 16-19 observations per group. Additionally, third, we should interpret all outcomes after correction for the multiple statistical comparisons of DLMO, SO, and SOL with the standard Bonferroni procedure. This procedure is under discussion for its usefulness and limitations, especially in small-numbered studies like this (Nakagawa 2004). This is why we finally decided to report all $p$ values instead of reporting significance categories. Fourth, TOA in this study neither depended on applied dosage nor DLMO; TOA was determined in a naturalistic way instead. This caused a wide range of DLMO-TOA intervals, which might have hampered the effects, especially of the lowest dosage. Due to the double-blind dose assigning, a dose-related TOA was not even possible. In future study design, this relationship should be taken into account; for instance with lower doses, a smaller DLMO-TOA interval is strived for.

Strength of the present study is that we studied individual responses. This differs from most melatonin trials, where response consisted of the shift of means of the different treatment groups. We applied a naturalistic design for timed melatonin administration, related to desired 
bedtime, but with focus on maximizing the DLMO-TOA interval.

The current finding, that the effects of melatonin treatment on sleep-wake rhythm are not related to the dosage in the pharmacologic dosing range $(>0.05 \mathrm{mg} / \mathrm{kg})$ but rather to the time of administration relative to the endogenous melatonin rhythm, is highly suggestive of melatonin's chronobiotic properties instead of primarily hypnotic pharmacological properties.

In conclusion, we do not expect that dosages higher than $0.15 \mathrm{mg} / \mathrm{kg}$ will exert larger shifting effects (based on the present data and our clinical experience). On the contrary, we recommend that dosages higher than $0.05 \mathrm{mg} / \mathrm{kg}$ for children with chronic insomnia are not necessary and probably should be avoided. Whether clinically effective dosages should be expected in the range achieving physiological serum levels or at least in dosages lower than $0.05 \mathrm{mg} / \mathrm{kg}$ cannot be inferred from the present data. Further dose-response studies should be performed in order to find the lowest possible dosage of melatonin in children, in combination with the most appropriate time of administration. The issue of bioavailability should be taken into account in further studies, with the sublingual tablet with ultralow dosages as an interesting candidate. Furthermore, additional long-term studies are needed to verify the safety of melatonin in children in the long run.

This study demonstrates that melatonin for treatment of chronic sleep onset insomnia in children is effective in a dosage of $0.05 \mathrm{mg} / \mathrm{kg}$ given $1-2 \mathrm{~h}$ before DLMO and before desired bedtime, resulting in 1-h shifts of DLMO and $\mathrm{SO}$ and a SOL reduction by $35 \mathrm{~min}$.

Acknowledgments We thank Y.G. van der Meer, Pharm D, and technicians (Gelderse Vallei Hospital, dep Pharmacy) for facilitating the trial, F. van Dijk (De Nieuwe Coster BV) for developing and supporting Medsys, B.C.G Dujardin and analysts (Gelderse Vallei Hospital, dep Laboratory of Clinical Chemistry and Haematology) for the analysis of all saliva samples, and Prof dr H. Vaarkamp (Utrecht University, Faculty of Veterinary Medicine, Pharmacy Department) for helpful discussions and critically reading the manuscript.

Disclosure statement Pharma Nord, Denmark supplied the melatonin to prepare the individual medication.

Open Access This article is distributed under the terms of the Creative Commons Attribution Noncommercial License which permits any noncommercial use, distribution, and reproduction in any medium, provided the original author(s) and source are credited.

\section{References}

Bendz LM, Scates AC (2010) Melatonin treatment for insomnia in pediatric patients with attention-deficit/hyperactivity disorder. Ann Pharmacother 44:185-191
Blader JC, Koplewicz HS, Abikoff H, Foley C (1997) Sleep problems of elementary school children. A community survey. Arch Pediatr Adolesc Med 151:473-480

Bojkowski CJ, Aldhous ME, English J, Franey C, Poulton AL, Skene DJ, Arendt J (1987) Suppression of nocturnal plasma melatonin and 6-sulphatoxymelatonin by bright and dim light in man. Horm Metab Res 19:437-440

Brainard GC, Rollag MD, Hanifin JP, van den Beld G, Sanford B (2000) The effect of polarized versus nonpolarized light on melatonin regulation in humans. Photochem Photobiol 71:766-770

Burgess HJ, Revell VL, Eastman CI (2008) A three pulse phase response curve to three milligrams of melatonin in humans. J Physiol 586:639-647

Cavallo A, Dolan LM (1996) 6-Hydroxymelatonin sulfate excretion in human puberty. J Pineal Res 21:225-230

Cavallo A, Ritschel WA (1996) Pharmacokinetics of melatonin in human sexual maturation. J Clin Endocrinol Metab 81:1882-1886

Coppola G, Iervolino G, Mastrosimone M, La Torre G, Ruiu F, Pascotto A (2004) Melatonin in wake-sleep disorders in children, adolescents and young adults with mental retardation with or without epilepsy: a double-blind, cross-over, placebo-controlled trial. Brain Dev 26:373-376

Dahl RE (1996) The impact of inadequate sleep on children's daytime cognitive function. Semin Pediatr Neurol 3:44-50

Griefahn B, Brode P, Blaszkewicz M, Remer T (2003) Melatonin production during childhood and adolescence: a longitudinal study on the excretion of urinary 6-hydroxymelatonin sulfate. J Pineal Res 34:26-31

Hoebert M, van der Heijden KB, van Geijlswijk IM, Smits MG (2009) Long-term follow-up of melatonin treatment in children with ADHD and chronic sleep onset insomnia. J Pineal Res 47:1-7

Jan MM (2000) Melatonin for the treatment of handicapped children with severe sleep disorders. Pediatr Neurol 23:229-232

Jan JE, Espezel H, Appleton RE (1994) The treatment of sleep disorders with melatonin. Dev Med Child Neurol 36:97-107

Jan JE, Hamilton D, Seward N, Fast DK, Freeman RD, Laudon M (2000) Clinical trials of controlled-release melatonin in children with sleep-wake cycle disorders. J Pineal Res 29:34-39

Klerman EB, Gershengorn HB, Duffy JF, Kronauer RE (2002) Comparisons of the variability of three markers of the human circadian pacemaker. J Biol Rhythms 17:181-193

Kushida CA, Chang A, Gadkary C, Guilleminault C, Carrillo O, Dement WC (2001) Comparison of actigraphic, polysomnographic, and subjective assessment of sleep parameters in sleepdisordered patients. Sleep Med 2:389-396

Lam JC, Mason TB (2007) Treatment of sleep disorders in children. Curr Treat Options Neurol 9:404-413

Lewy AJ, Cutler NL, Sack RL (1999) The endogenous melatonin profile as a marker for circadian phase position. J Biol Rhythms 14:227-236

Lewy AJ, Emens JS, Bernert RA, Lefler BJ (2004) Eventual entrainment of the human circadian pacemaker by melatonin is independent of the circadian phase of treatment initiation: clinical implications. J Biol Rhythms 19:68-75

Lewy AJ, Emens J, Jackman A, Yuhas K (2006) Circadian uses of melatonin in humans. Chronobiol Int 23:403-412

Littner M, Kushida CA, Anderson WM, Bailey D, Berry RB, Davila DG, Hirshkowitz M, Kapen S, Kramer M, Loube D, Wise M, Johnson SF (2003) Practice parameters for the role of actigraphy in the study of sleep and circadian rhythms: an update for 2002 . Sleep 26:337-341

McArthur AJ, Budden SS (1998) Sleep dysfunction in Rett syndrome: a trial of exogenous melatonin treatment. Dev Med Child Neurol 40:186-192

Morgenthaler TI, Lee-Chiong T, Alessi C, Friedman L, Aurora RN, Boehlecke B, Brown T, Chesson AL Jr, Kapur V, Maganti R, Owens J, Pancer J, Swick TJ, Zak R (2007) Practice parameters 
for the clinical evaluation and treatment of circadian rhythm sleep disorders. An American Academy of Sleep Medicine report. Sleep 30:1445-1459

Nagtegaal E, Peeters T, Swart W, Smits M, Kerkhof G, van der Meer $\mathrm{G}$ (1998) Correlation between concentrations of melatonin in saliva and serum in patients with delayed sleep phase syndrome. Ther Drug Monit 20:181-183

Nakagawa S (2004) A farewell to Bonferroni: the problems of low statistical power and publication bias. Behav Ecol 15:2

Owens JA, Moturi S (2009) Pharmacologic treatment of pediatric insomnia. Child Adolesc Psychiatr Clin N Am 18:1001-1016. doi:10.1016/j.chc.2009.04.009

Pandi-Perumal SR, Srinivasan V, Spence DW, Cardinali DP (2007) Role of the melatonin system in the control of sleep: therapeutic implications. CNS Drugs 21:995-1018

Ring A, Stein D, Barak Y, Teicher A, Hadjez J, Elizur A, Weizman A (1998) Sleep disturbances in children with attention-deficit/ hyperactivity disorder: a comparative study with healthy siblings. J Learn Disabil 31:572-578

Ruff RL (1998) Electrophysiology of postsynaptic activation. Ann NY Acad Sci 841:57-70

Schmidt F, Penka B, Trauner M, Reinsperger L, Ranner G, Ebner F, Waldhauser F (1995) Lack of pineal growth during childhood. J Clin Endocrinol Metab 80:1221-1225

Smits MG, Nagtegaal EE, van der Heijden J, Coenen AM, Kerkhof GA (2001) Melatonin for chronic sleep onset insomnia in children: a randomized placebo-controlled trial. J Child Neurol 16:86-92

Smits MG, van Stel HF, van der Heijden K, Meijer AM, Coenen AM, Kerkhof GA (2003) Melatonin improves health status and sleep in children with idiopathic chronic sleep-onset insomnia: a randomized placebo-controlled trial. J Am Acad Child Adolesc Psychiatry 42:1286-1293

Stone BM, Turner C, Mills SL, Nicholson AN (2000) Hypnotic activity of melatonin. Sleep 23:663-669

Sutcliffe AG, Wong IC (2006) Rational prescribing for children. BMJ $332: 1464-1465$
Szeinberg A, Borodkin K, Dagan Y (2006) Melatonin treatment in adolescents with delayed sleep phase syndrome. Clin Pediatr 45:809-818

Van der Heijden KB, Smits MG, van Someren EJ, Gunning WB (2005) Prediction of melatonin efficacy by pretreatment dim light melatonin onset in children with idiopathic chronic sleep onset insomnia. J Sleep Res 14:187-194

Van der Heijden KB, Smits MG, Van Someren EJ, Ridderinkhof KR, Gunning WB (2007) Effect of melatonin on sleep, behavior, and cognition in ADHD and chronic sleep-onset insomnia. J Am Acad Child Adolesc Psychiatry 46:233-241

Van Geijlswijk IM, Didden R, van der Heijden KB, Smits MG (2010) Onset and stability of melatonin treatment effect in childhood sleep onset insomnia. Sleep Sci 3:16-21

Vitiello B (2007) Research in child and adolescent psychopharmacology: recent accomplishments and new challenges. Psychopharmacology 191:5-13

Voultsios A, Kennaway DJ, Dawson D (1997) Salivary melatonin as a circadian phase marker: validation and comparison to plasma melatonin. J Biol Rhythms 12:457-466

Waldhauser F, Weiszenbacher G, Tatzer E, Gisinger B, Waldhauser M, Schemper M, Frisch H (1988) Alterations in nocturnal serum melatonin levels in humans with growth and aging. J Clin Endocrinol Metab 66:648-652

Wasdell MB, Jan JE, Bomben MM, Freeman RD, Rietveld WJ, Tai J, Hamilton D, Weiss MD (2008) A randomized, placebo-controlled trial of controlled release melatonin treatment of delayed sleep phase syndrome and impaired sleep maintenance in children with neurodevelopmental disabilities. J Pineal Res 44:57-64

Weiss MD, Wasdell MB, Bomben MM, Rea KJ, Freeman RD (2006) Sleep hygiene and melatonin treatment for children and adolescents with ADHD and initial insomnia. J Am Acad Child Adolesc Psychiatry 45:512-519

Werner H, Molinari L, Guyer C, Jenni OG (2008) Agreement rates between actigraphy, diary, and questionnaire for children's sleep patterns. Arch Pediatr Adolesc Med 162:350-358 